\title{
Attenuating effect of Acorus calamus extract in chronic constriction injury induced neuropathic pain in rats: an evidence of anti-oxidative, anti-inflammatory, neuroprotective and calcium inhibitory effects
}

Arunachalam Muthuraman and Nirmal Singh ${ }^{*}$

\begin{abstract}
Background: Acorus calamus (family: Araceae), is an indigenous plant, traditionally it is used as an ingredient of various cocktail preparations and for the management of severe inflammatory disorders in Indian system of medicine. Present study investigated the attenuating role of Acorus calamus plant extract in chronic constriction injury (CCl) of sciatic nerve induced peripheral neuropathy in rats.

Methods: Hot plate, plantar, Randall Selitto, Von Frey Hair, pin prick, acetone drop, photoactometer and rota-rod tests were performed to assess degree of thermal, radiant, mechanical, chemical sensation, spontaneous motor activity and motor co-ordination changes respectively, at different time intervals i.e., day 0, 1, 3, 6, 9, 12, 15, 18 and 21. Tissue myeloperoxidase, superoxide anion and total calcium levels were determined after $21^{\text {st }}$ day to assess biochemical alterations. Histopathological evaluations were also performed. Hydroalcoholic extract of Acorus calamus (HAE-AC, 100 and $200 \mathrm{mg} / \mathrm{kg}$, p.o.) and pregabalin (10 mg/kg, p.o.) were administered from the day of surgery for 14 days.
\end{abstract}

Results: $\mathrm{CCl}$ of sciatic nerve significantly induced thermal, radiant, mechanical hyperalgesia and thermal, chemical, tactile allodynia, along with increase in the levels of superoxide anion, total calcium and myeloperoxidase activity. Moreover significant histological changes were also observed. HAE-AC attenuated CCI induced development of painful behavioural, biochemical and histological changes in a dose dependent manner similar to that of pregabalin serving as positive control.

Conclusions: Acorus calamus prevented $\mathrm{CCl}$ induced neuropathy which may be attributed to its multiple actions including anti-oxidative, anti-inflammatory, neuroprotective and calcium inhibitory actions.

\section{Background}

Pain after injury to the nervous system (neuropathic pain) is a major chronic pain condition that remains difficult to treat. Both peripheral and central mechanisms of neuropathic pain have been proposed by various researchers [1-4]. Neuropathic pain associated with peripheral nerve injury is characterized by the sensory abnormalities such as unpleasant abnormal sensation

\footnotetext{
* Correspondence: nirmal_puru@rediffmail.com

Department of pharmaceutical sciences and drug research, Punjabi
} university, Patiala-147002, India (dysesthesia), an increased response to painful stimuli (hyperalgesia), and pain in response to a stimulus that does not normally provoke pain (allodynia) [4]. Peripheral neuropathic pain is frequently observed in patients with long standing diabetes, cancer, AIDS, leprosy, cervical disc protrusion and foraminotomy and after surgery [5-9]. Chronic constriction injury of sciatic nerve induced painful neuropathy is a widely employed model for induction of neuropathic pain in experimental animals [10]. CCI induced neuropathy in experimental animals mimics Complex Regional Pain Syndrome - reflex

\section{Ciomed Central}


sympathetic dystrophy (CRPS-RSD) in humans [11-13], which is common following fracture, total knee arthroplasty and stroke [14-17].

Conventional analgesics like non-steroidal antiinflammatory drugs and opioids are in-effective clinically in attenuating neuropathic pain. Further, tricyclic anti-depressants (i.e., amitriptyline, nortriptyline and imipramine) and anti-convulsants (i.e., phenytoin, carbamazepine, gabapentin, lamotrigine and topiramate) have also been reported to produce anti-allodynic effects in neuropathy [18-22]. However, these drugs are reported to exhibit a wide spectrum of adverse effects which limit their full clinical exploitation in management of painful neuropathy [23-25]. Moreover, none of the medications assessed in randomized controlled studies conducted has been found effective in CRPS [26-28].

Preclinically, various studies have reported herbal medicine to produce the beneficial effect in the management of painful neuropathy i.e., Aconiti tuber, Lindera angustifolia, Teucrium polium, Phyllanthus emblica, Vochysia divergens, Cannabis sativa, Nigella sativa, Ocimum sanctum and Ginkgo biloba [29-33]. Therefore, there is an ample scope of new medicine from plant origin to combat the neuropathic pain conditions. Some recent clinical reports have also advocated beneficial effect of drugs from plant origin in neuropathic pain conditions [34-36].

Acorus calamus (family: Araceae), is an indigenous plant, traditionally, it is used as an ingredient of various cocktail preparations employed for the treatment and management of headache, migraine, body ache and severe inflammatory pain of the Unani, Ayurveda and local health care systems in Indian system of medicine. Fresh rhizome part extraction and/or decoction of Acorus calamus commonly used to relieve the muscle, joint, vascular and nerve injury associated severe inflammatory and neuropathic pain in south Indian population. Phytochemically it has reported the presence of glycosides, flavonoids, saponins, tannins, polyphenolic compounds, mucilage, volatile oil and bitter principles $[37,38]$. Experimental reports have indicated that, the rhizome part of the Acorus calamus plant has several medicinal properties, which is used in the treatment of insomnia, melancholia, neurosis, remittent fevers, delirium and hysteria [38]. The aqueous and hydroalcoholic extracts have been shown to express the hypolipidemic and neuropharmacological activities [39,40]. In our recent study, hydroalcoholic extract of Acorus calamus rhizome part has been shown to exert beneficial effect in tibial and sural nerve transection induced neuropathic pain in rats [41]. However usefulness of Acorus calamus in chronic constriction injury of sciatic nerve induced painful peripheral neuropathy remains to be explored. Therefore, the present study has been designed to investigate the ameliorative effect of Acorus calamus in chronic constriction injury of sciatic nerve induced neuropathic pain in rats. Pregabalin a selective $\mathrm{Ca}_{\mathrm{v}} 2.2\left(\alpha_{2}-\delta\right.$ subunit) channel antagonist served as positive control in this study.

\section{Methods}

\section{Plant material}

The fresh rhizome part of Acorus calamus were collected at Kodaikanal of Tamilnadu, India and authenticated through department of botany, American college, Madurai district, Tamilnadu. Plant sample has been kept in voucher specimen (PUP-218/2009-2010) at Punjabi University, Patiala for future reference. After authentication, fresh rhizome of $A C$ were collected, cleaned thoroughly with distilled water and dried under shade. The shade dried rhizome was pulverized in a mechanical grinder to obtain coarse powder (sieve no.10/40).

\section{Extraction}

The coarsely powdered plant material was subjected to extraction with mixture of ethanol:water $(1: 1,50 \%)$ at room temperature. After completion of extraction, the solvent was completely removed by vacuum drying at low temperature $\left(<50^{\circ} \mathrm{C}\right)$. The yield of hydroalcoholic extract was found to be $26.4 \%(\mathrm{w} / \mathrm{w})$. The crude extracts were evaluated for absence of $\beta$-asarone by measuring the extinction at 253 and $303 \mathrm{~nm}$ by HPLC method. The extract was found to contain saponins, glycosides, flavonoids and tannins. This hydroalcoholic extract was used to explore its potential in chronic constriction injury of sciatic nerve induced painful neuropathy in rat.

\section{Chemicals}

DTNB [5,5'-dithio, bis (2-nitro benzoic acid)], NBT (Nitro Blue Tetrazolium) (Sigma Aldrich, USA), BSA (Bovine Serum Albumin) (Sisco Research Laboratories Pvt. Ltd., Mumbai, India), hexadecyl trimethyl ammonium bromide (HETAB), O-dianisidine hydrochloride (S.D. Fine, Mumbai India), Folin-Ciocalteu's phenol reagent (Merck Ltd. Mumbai, India) were procured for the present study. All the chemicals used in the present study were of analytical grade.

\section{Experimental animals}

Wistar rats (either sex), weighing between 200-230 g [procured from disease free small animal house, CCSHaryana Agricultural University, Hisar] were used in the present study. The animals given free access to water and standard laboratory diet (Kisan Feeds Ltd., Mumbai, India) and were exposed to $12 \mathrm{~h}$ light and dark cycles. The experimental protocol was duly approved by the institutional animal ethics committee of Punjabi University, Patiala (Punjab), India, and the care of the animals 
was carried out as per guidelines of the committee for the purpose of control and supervision of experiments on animals, Ministry of environment and forest, Government of India (Reg. No.: 107/1999/CPCSEA).

\section{Induction of peripheral neuropathy by chronic constriction injury (CCl)}

Peripheral neuropathy was induced in rats by chronic constriction injury as described method of Bennett and Xie [10] with slight modifications of Sommer and Schafers [42]. In brief, the rats were anesthetized with thiopental sodium $(35 \mathrm{mg} / \mathrm{kg}$ i.p.). The hair of the rat's lower back in thigh region of left paw was shaved, and the skin was sterilized with povidone-iodine (Betadine $\left.^{\mathrm{TM}}\right)$. The skin of the lateral surface of the left thigh was incised and a cut was made directly through the biceps femoris muscles to expose the sciatic nerve. Four ligatures (silk 4-0), were placed around the nerve proximal part of the trifurcation with a distance of $1 \mathrm{~mm}$ between each ligature. The ligatures were loosely tied until a short flick of the ipsilateral hind limb was observed. After performing nerve ligation, muscular and skin layer was immediately sutured with thread and topical antibiotic was applied at once. Nociceptive threshold was assessed before and after performing surgery on different days i.e. $0,1,3,6,9,12,15,18$, and $21^{\text {st }}$ day.

\section{Experimental protocol}

Ten groups, each comprising of six Wistar rats, were employed in the present study.

Group I (Normal control): Rats were not subjected to any surgical procedure and were kept for 3 weeks. The behavioural tests were performed on the different days, i.e., day $0,1,3,6,9,12,15,18$ and $21^{\text {st }}$. Thereafter, all the animals were sacrificed subjected to biochemical analysis for the estimation of total protein, superoxide anion generation and total calcium in sciatic nerve tissue and myeloperoxidase activity in the surrounding muscular tissue sample.

Group II (Sham control): Rats were subjected to a surgical procedure (on day 0 ) to expose the sciatic nerve without any ligation. The behavioural tests were employed before performing the surgery and after $24 \mathrm{hr}$ of surgery (i.e., day $1^{\text {st }}$ ) on different days as described in group I. The biochemical analysis was also done as mentioned in group I.

Group III (Chronic Constriction Injury, CCI): Rats were subjected to a surgical procedure to expose and four loose ligation of the sciatic nerve. The behavioural tests and the biochemical parameters were assessed as mentioned in group I.

Group IV (Vehicle in CCI): Carboxy methyl cellulose (CMC) $(0.5 \% \mathrm{w} / \mathrm{v}$, p.o. $)$ was administered for 14 days (starting from day $1^{\text {st }}$ ) in rats subjected to CCI. The behavioural tests and the biochemical parameters were assessed as mentioned in group I.

Groups V ( $A C$ per se): Hydro-alcoholic extract of $A C$ $(200 \mathrm{mg} / \mathrm{kg}$, p.o. $)$ was administered for 14 days in normal rats, starting from the day $1^{\text {st }}$. The behavioural tests and the biochemical parameters were assessed as mentioned in group I.

Groups VI (Pregabalin per se): Pregabalin $(10 \mathrm{mg} / \mathrm{kg}$, p.o.) was administered for 14 days in normal rats, starting from the day $1^{\text {st }}$. The behavioural tests and the biochemical parameters were assessed as mentioned in group I.

Groups VII and VIII (Low and high dose of $A C$ in CCI): Hydro-alcoholic extract of $A C$ (100 and $200 \mathrm{mg} /$ $\mathrm{kg}$, p.o.) was administered for 14 days in rats subjected to CCI, starting from the day $1^{\text {st }}$. The behavioural tests and the biochemical parameters were assessed as mentioned in group I.

Groups IX (Pregabalin in CCI): Pregabalin $(10 \mathrm{mg} / \mathrm{kg}$, p.o.) was administered for 14 days in rats subjected to $\mathrm{CCI}$, starting from the day $1^{\text {st }}$. The behavioural tests and the biochemical parameters were assessed as mentioned in group I.

Groups X (Spontaneous motor activity and motor coordination):

For testing effect on spontaneous motor activity and motor-co-ordination, photoactometer test and rota-rod tests respectively were employed. Each animal was first placed in photoactometer for 5 minutes followed by rota-rod test. After $1^{\text {st }}$ day measurements the animals were treated with hydro-alcoholic extract of $A C$ $(200 \mathrm{mg} / \mathrm{kg}$, p.o. daily) for next 14 days. The test was repeated on $14^{\text {th }}$ day after 1 hour of drug administration.

\section{Behavioural studies \\ Heat hyperalgesic and allodynia test}

Heat hyperalgesia and allodynia of the hind paw were assessed using Eddy's hot plate as described method of Eddy et al. [43], for assessing the reactivity to noxious and non-noxious thermal stimuli respectively. The rats were placed on the top of a controlled preheated (52.5 \pm $0.5^{\circ} \mathrm{C}$ for hyperalgesia; $45 \pm 0.5^{\circ} \mathrm{C}$ for allodynia) and maintained hot plate surface, allowing access to the left hind paw withdrawal response to degree of the nociceptive threshold. The cut-off times of $20 \mathrm{~s}$ for hyperalgesia and $30 \mathrm{~s}$ for allodynia were maintained.

\section{Radiant heat hyperalgesic test}

Radiant heat hyperalgesia of the left hind paw was assessed using the radiant heat lamp source as described method of Hargreaves et al. [44], for assessing the reactivity to noxious thermal stimuli. The intensity of the radiant heat stimulus was maintained at $25 \pm 0.1^{\circ} \mathrm{C}$. 
Response of left hind paw withdrawal threshold was noted. Cut-off time of $20 \mathrm{~s}$ was maintained.

\section{Cold chemical allodynia test}

Cold-allodynia of the hind paw was assessed using acetone drop method as described method of Choi et al. [45], with slight modification, for assessing the reactivity to non-noxious cold chemical stimuli. The rats were placed on the top of a wire mesh grid, allowing access to the hind paws. Acetone $(0.1 \mathrm{ml})$ was sprayed on the plantar surface of left hind paw of rat. Cold chemical sensitive reaction with respect to either paw licking, shaking or rubbing the left hind paw was observed and recorded as paw lifting duration for $20 \mathrm{~s}$ test period.

\section{Static mechanical hyperalgesic test}

Mechanical (static) nociceptive threshold as an index of mechano-hyperalgesia were assessed by pressure stimulation method as described method of Randall and Selitto [46]. Briefly, nociceptive threshold, expressed in grams, as measured by applying increasing pressure to the left hind paw. Withdrawal of left hind paw or vocalization response was noted to assess the static mechanical nociceptive threshold. The cut-off pressure of $450 \mathrm{~g}$ was maintained.

\section{Tactile mechanical hyperalgesic test}

Mechanical (tactile) hyperalgesia was assessed by the pinprick test as described in the method of Erichsen and Blackburn-Munro [47]. The plantar surface of the injured left hind paw was touched with the point of the bent 18 gauge needle (at $90^{\circ}$ angle) at intensity sufficient to produce a reflex withdrawal response in normal non-operated animals, but at an intensity which was insufficient to penetrate the skin in all other group. The duration of the paw withdrawal was recorded in seconds. A cut-off time of $20 \mathrm{~s}$ was maintained.

\section{Mechanical allodynia test}

Mechanical allodynia (non-noxious mechanical stimuli) was assessed as described by Chaplan et al. [48]. Briefly, calibrated nylon filaments [Von Frey Hair, total 20 filaments numbered $1.65,2.36,2.44,2.83,3.22,3.61,3.84$, $4.08,4.17,4.31,4.58,4.74,4.83,5.07,5.18,5.48,5.88$, $6.10,6.45$, and 6.65], in terms of different bending forces $(0.008,0.02,0.04,0.07,0.16,0.4,0.6,1,1.4,2,4,6,8,10$, $15,26,60,100,180,300 \mathrm{~g})$, were applied to the mid plantar surface of left hind paw. The filaments were applied ten times, starting with the softest and continuing in ascending order of stiffness. A brisk withdrawal of the left hind limb was considered a positive response. The criterion for the threshold value, in grams, was equal to the filament evoking a withdrawal threshold of the left hind paw 5 times out of 10 trials i.e., $50 \%$ response.

\section{Motor co-ordination test}

Motor co-ordination (grip muscle strength) was evaluated by a rota-rod device as described by Jones and
Roberts [49] with slight modification of Muthuraman et al. [32]. Rats were placed for one minute on the rotating $\operatorname{rod}(25 \mathrm{rpm})$. The time taken for the falling from the roller, during one minute period was recorded.

\section{Spontaneous locomotor (exploratory) activity test}

Photoactometer test was employed to assess the effect of drug treatment on spontaneous motor (exploratory) activity. Each animal was observed for a period of $5 \mathrm{~min}$ in a square closed field arena $(30 \times 30 \times 30 \mathrm{~cm})$ equipped with 6 photocells in the outer wall. Interruptions of photocell beams (locomotor/exploratory action) were recorded by means of a 6 digits counter [50].

\section{Biochemical estimation}

All the animals were sacrificed on $21^{\text {st }}$ day after surgery with chemical euthanasia $(50 \mathrm{mg} / \mathrm{kg}$, i.p., thiopental sodium). The injury site and distal portions of the sciatic nerve and the tissue beneath the sciatic nerve were isolated immediately. Further, the samples were kept in the humidity chamber (maintained at $85 \%$ relative humidity and $37^{\circ} \mathrm{C}$ temperature) to remove and maintain the moisture content of the collected samples. The sciatic nerve homogenate $(10 \%, \mathrm{w} / \mathrm{v})$ was prepared with $0.1 \mathrm{M}$ Tris- $\mathrm{HCl}$ buffer ( $\mathrm{pH}$ 7.4), and deionised water for total protein and total calcium estimation respectively. Superoxide anion measurement was carried out in sciatic nerve as described method of Wang et al. [51]. Further, surrounding muscular tissue was homogenates with phosphate buffer ( $\mathrm{pH} 7.4)$ and employed for myeloperoxidase (MPO) estimation.

\section{Estimation of total protein content}

Protein concentration was estimated according to the method of Lowry et al. [52], Using Bovine serum albumin (BSA) as a standard. The absorbance was determined spectrophotometrically at $750 \mathrm{~nm}$.

\section{Estimation of superoxide anion generation}

The sciatic nerve superoxide anion generation was estimated in terms of reduced nitroblue tetrazolium (NBT) as described in the method of Wang et al. [51]. Briefly, sciatic nerve homogenate react with NBT under certain chemical environment to form formazan as an index of superoxide anion generation. The absorbance of formazan was determined spectrophotometrically at $540 \mathrm{~nm}$.

The quantity of NBT reduction $=\mathrm{A} \times \mathrm{V} /(\mathrm{T} \times \mathrm{Wt} \times \varepsilon \times \mathrm{l})$,

Where $\mathrm{A}$ is the absorbance of blue formazan at 540 $\mathrm{nm}, \mathrm{V}$ is the volume of the solution, $\mathrm{T}$ is the time period (90 minutes) during which rings were incubated with NBT, Wt is the blotted wet weight of the sciatic nerve, $\varepsilon$ is the extinction coefficient of blue formazan (i.e., $0.72 \mathrm{l} / \mathrm{mmol} / \mathrm{mm}$ ), and $\mathrm{l}$ is the length of the light path. Results were reported as picomoles per minute per milligram wet weight of sciatic nerve.

\section{Estimation of myeloperoxidase (MPO) activity}

The myeloperoxidase activity was measured by a method described by Grisham et al. [53]. The absorbance was read 
spectrophotometrically at $460 \mathrm{~nm}$. One unit of the myeloperoxidase activity is defined as that which would produce a change in absorbance of $1.0 \mathrm{unit} / \mathrm{min}$ at $\mathrm{pH} 7.0$ and $25^{\circ}$ $\mathrm{C}$, calculated from the initial rate of reaction with peroxide $(1 \mu \mathrm{M})$ as the substrate. The results were expressed as myeloperoxidase activity units per milligram of protein at one minute.

\section{Estimation of total calcium}

Total calcium levels were estimated in sciatic nerve according to the method of Severinghaus and Ferrebee [54] with slight modification of Muthuraman et al. $[32,55]$. Briefly, sciatic nerve homogenate was mixed with $1 \mathrm{ml}$ of trichloroacetic acid (4\%) in ice cold conditions and centrifuged at 2000 r.p.m. for 10 minutes. The clear supernatant was used for the estimation of total calcium ion by atomic emission spectroscopy at $556 \mathrm{~nm}$.

\section{Histopathological evaluation}

Samples of distal portion of sciatic nerve were stored in the fixative solution ( $10 \%$ formalin) and cut into $4 \mu \mathrm{m}$ thickness. Staining was done by using hematoxylin and eosin as described by method of Sudoh et al. [56]. Nerve sections were analyzed qualitatively under light microscope $(450 \mathrm{X})$ for axonal degeneration.

\section{Statistical analysis}

All the results were expressed as mean \pm standard error of means (S.E.M.). The data from the behavioural results were statistically analyzed by two-way analysis of variance followed by Bonferonni's posthoc-test using GraphPad Prism Version-5.0 software. The data from the biochemical results were statistically analyzed using one-way ANOVA followed by Tukey's multiple range tests. The $p$-value $<0.05$ was considered to be statistically significant.

\section{Results}

Administration of hydroalcoholic extract of Acorus calamus did not produce any significant effect on motorcoordination and spontaneous motor (locomotor or exploratory) activity of rats as tested on rota-rod and photoactometer respectively (data not shown).

\section{Effect on heat hyperalgesia and allodynia}

Chronic constriction injury resulted in a significant development of thermal hyperalgesia (Figure 1) and allodynia (Figure 2) noted by decrease in left hind paw withdrawal threshold as compared to sham groups. Administration of hydroalcoholic extract of $A C(100$ and $200 \mathrm{mg} / \mathrm{kg}$, p.o. $)$

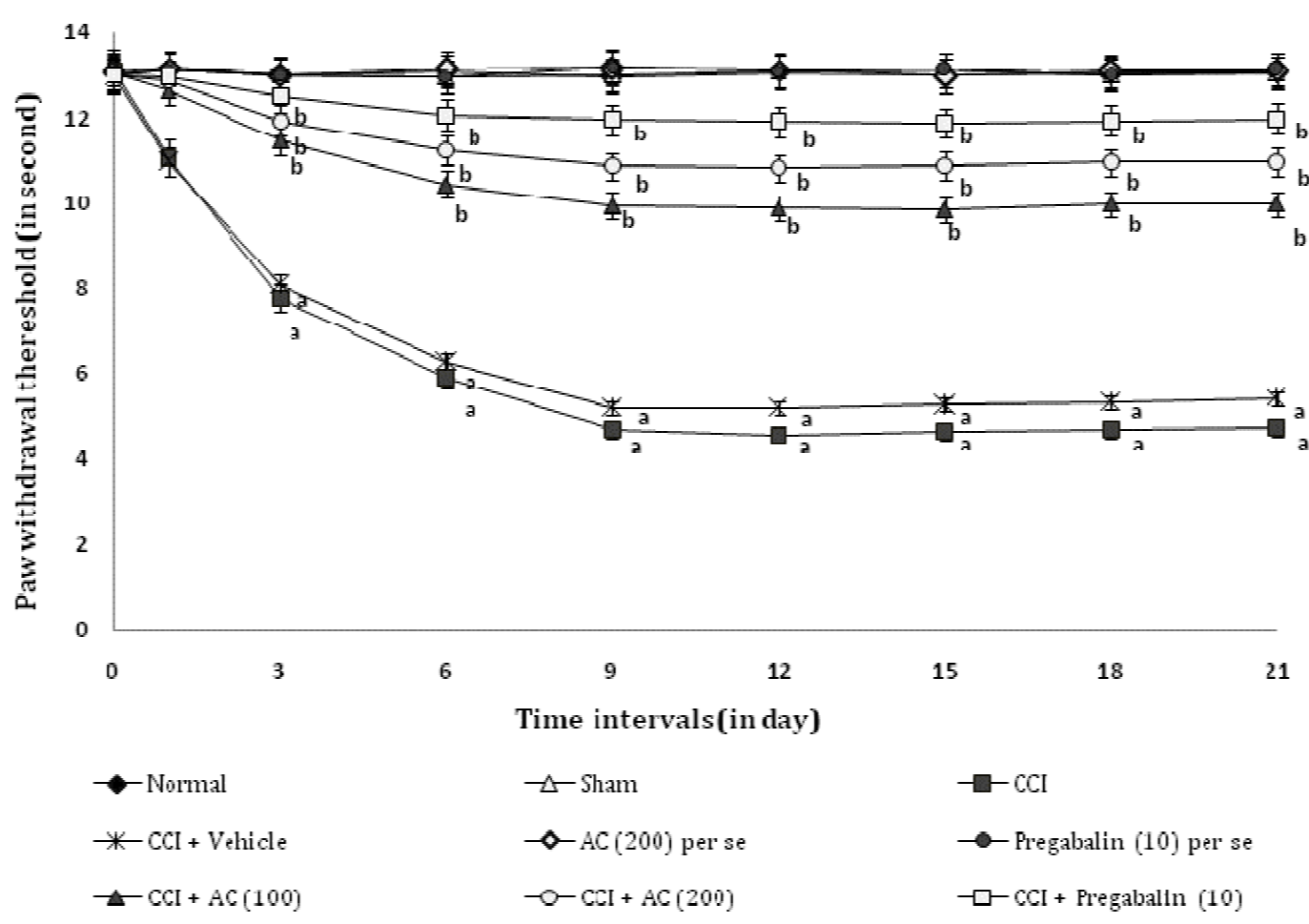

Figure 1 Effect of Acorus calamus on heat hyperalgesia assessed by the noxious thermal sensation evoked ipsilateral hind paw withdrawal threshold. Digits in parentheses indicate the dose of Acorus calamus and pregabalin in $\mathrm{mg} / \mathrm{kg}$. Data expressed as mean \pm standard error of mean (SEM), each group consist of six $(n=6)$ Wistar rat. ${ }^{a} p<0.05$ vs sham control group. ${ }^{\mathbf{b}} p<0.05$ vs CCl control group. 


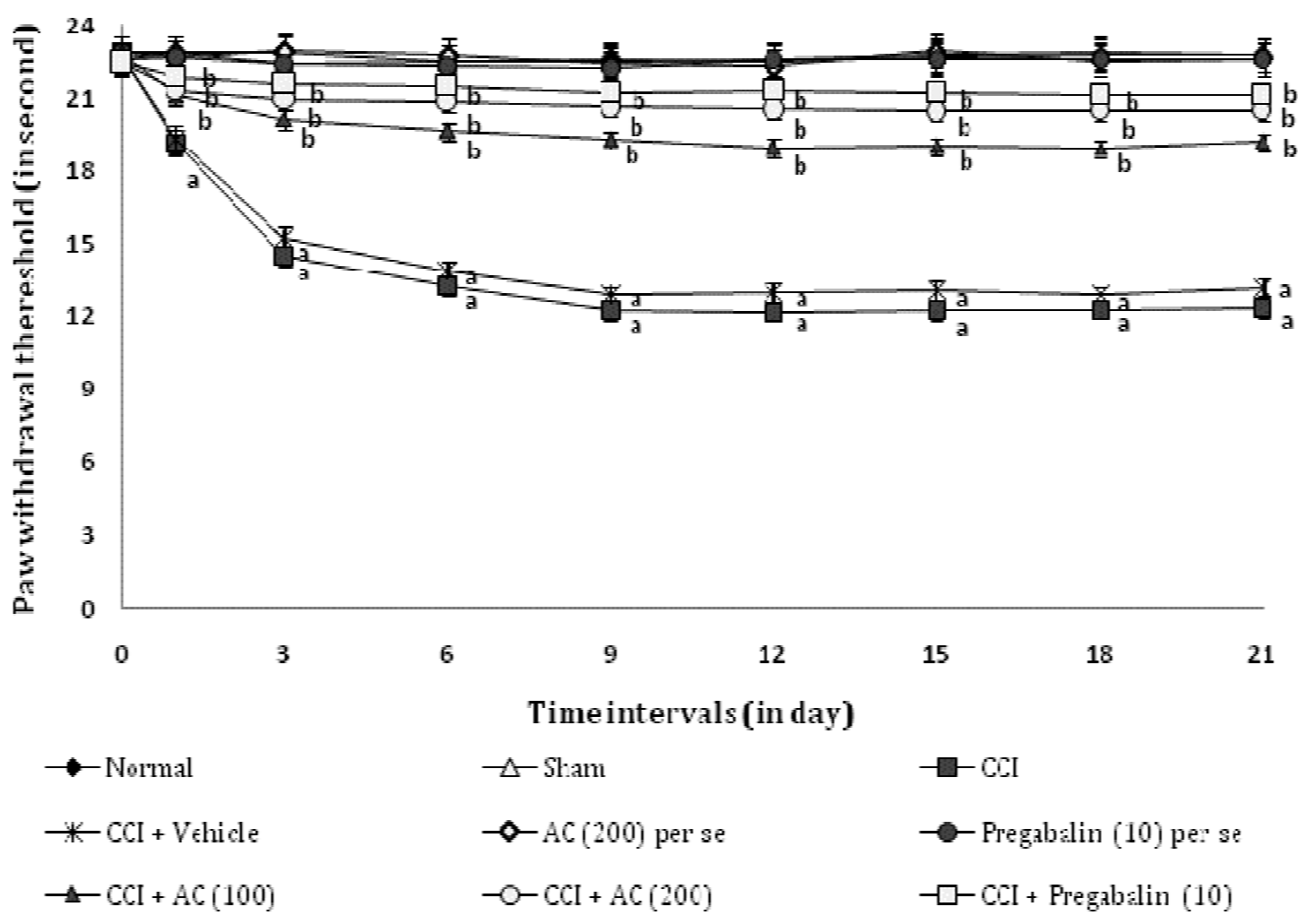

Figure 2 Effect of Acorus calamus on heat allodynia assessed by the non-noxious thermal sensation evoked ipsilateral hind paw withdrawal threshold. Digits in parentheses indicate the dose of Acorus calamus and pregabalin in $\mathrm{mg} / \mathrm{kg}$. Data expressed as mean \pm standard error of mean (SEM), each group consist of six $(n=6)$ Wistar rat. ${ }^{a} p<0.05$ vs sham control group. ${ }^{\mathbf{b}} p<0.05$ vs CCI control group.

attenuated $\mathrm{CCI}$ induced decrease in the nociceptive threshold for thermal hyperalgesia $[63.02 \% \pm 0.041$ and $74.54 \% \pm 0.025$ (inhibition \pm SEM) $]$ and allodynia $[66.08 \%$ \pm 0.019 and $79.98 \% \pm 0.033$ (inhibition \pm SEM) $]$ in a dose dependent manner. Treatment of pregabalin also produced similar effects $[86.8 \% \pm 0.026$ for thermal hyperalgesia, and $86.84 \% \pm 0.017$ for allodynia (inhibition \pm SEM)] . However, the vehicle administration did not modulate $\mathrm{CCI}$ induced thermal hyperalgesia and allodynia. Moreover, $A C$ as well as pregabalin per se did not show any significant effect on above mentioned behaviour.

\section{Effect on radiant heat hyperalgesia}

CCI resulted in a significant development of radiant heat hyperalgesia (Figure 3) noted by decrease in left hind paw withdrawal threshold as compared to sham group. Administration of hydroalcoholic extract of $A C$ (100 and $200 \mathrm{mg} / \mathrm{kg}$, p.o.) attenuated CCI induced decrease in the nociceptive threshold for thermal hyperalgesia $[75.6 \% \pm 0.021$ and $82.23 \% \pm 0.028$ (inhibition \pm SEM)] in a dose dependent manner. Treatment of pregabalin also produced similar effects $[89.88 \% \pm 0.024$ (inhibition \pm SEM) $]$. However, the vehicle administration did not modulate $\mathrm{CCI}$ induced thermal hyperalgesia. Moreover, $A C$ as well as pregabalin per se did not show any significant effect on above mentioned behaviour.

\section{Effect on cold chemical allodynia}

CCI resulted in a significant development of cold chemical allodynia as indicated by increase in the left hind paw lifting duration using acetone drop test method (Figure 4), as compared to sham group. Administration of $A C(100$ and $200 \mathrm{mg} / \mathrm{kg})$ significantly attenuated CCI induced increase in paw lifting duration i.e. cold allodynia $[65.67 \% \pm 0.031$ and $73.36 \% \pm 0.016$ (inhibition \pm SEM)] in a dose dependent manner. Treatment of pregabalin also produced similar effects $[84.6 \% \pm 0.017$ (inhibition \pm SEM)]. However, the vehicle administration did not modulate CCI induced cold allodynia. Moreover, $A C$ as well as pregabalin per se did not show any significant effect on above mentioned behaviour.

\section{Effect on static mechanical hyperalgesia}

CCI resulted in the development of static mechanical hyperalgesia as reflected by a significant increase in the 


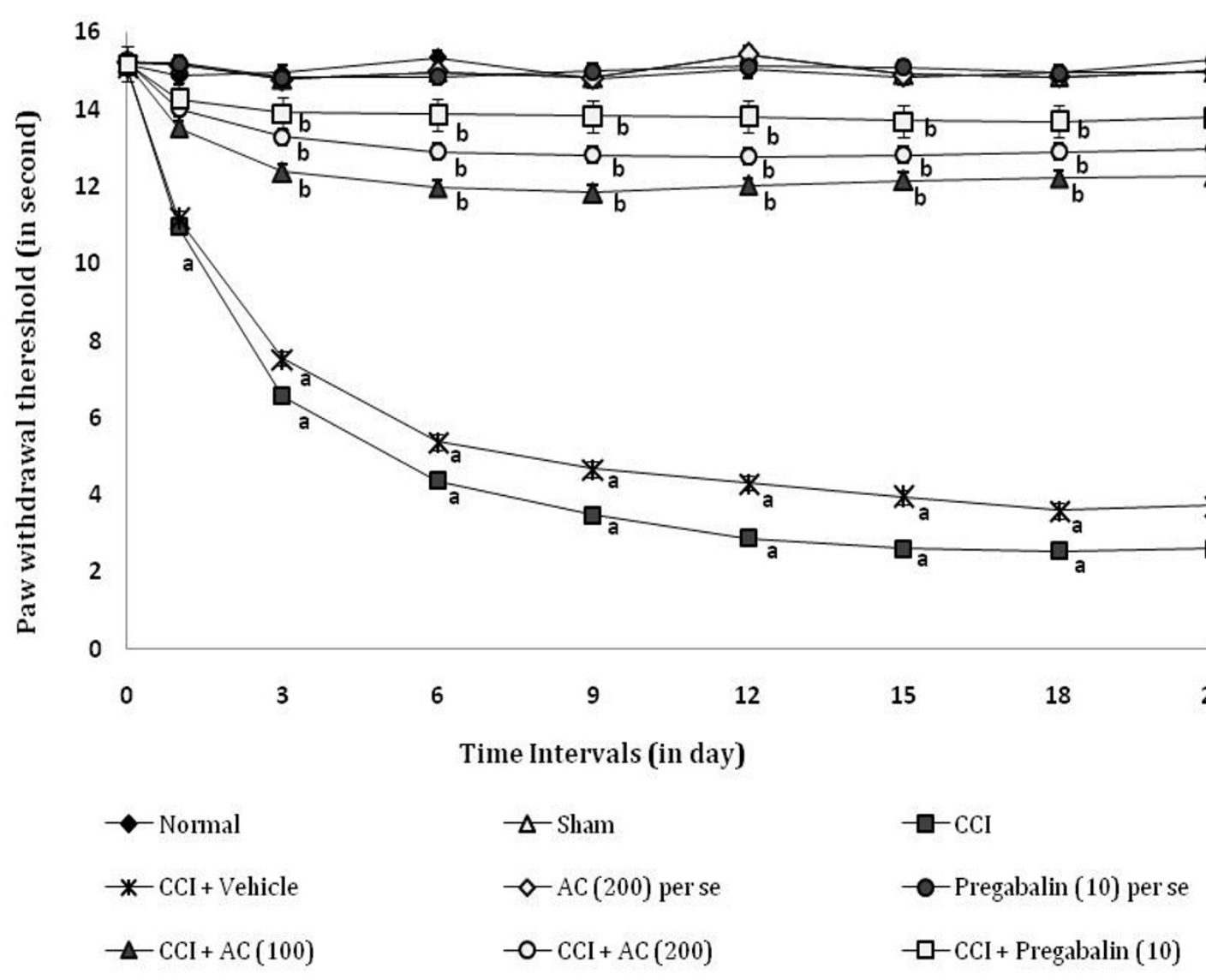

Figure 3 Effect of Acorus calamus on radiant heat hyperalgesia assessed by the noxious thermal sensation evoked ipsilateral hind paw withdrawal threshold. Digits in parentheses indicate the dose of Acorus calamus and pregabalin in $\mathrm{mg} / \mathrm{kg}$. Data expressed as mean \pm standard error of mean (SEM), each group consist of six $(n=6)$ Wistar rat. ${ }^{\mathbf{a}} p<0.05$ vs sham control group. ${ }^{\mathbf{b}_{p}}<0.05$ vs $C C l$ control group.

left hind paw withdrawal threshold in the paw pressure test (Figure 5), as compared to sham group. Administration of hydroalcoholic extract of $A C(100$ and $200 \mathrm{mg} /$ $\mathrm{kg}$ ) attenuated CCI induced increase in the hind paw withdrawal threshold i.e. static mechanical hyperalgesia $[66.42 \% \pm 0.034$ and $81.54 \% \pm 0.025$ (inhibition \pm SEM)] in a dose dependent manner. Treatment of pregabalin also produced similar effects $[90.9 \% \pm 0.028$ (inhibition \pm SEM)]. However, the vehicle administration did not modulate CCI induced mechanical hyperalgesia. Moreover, $A C$ as well as pregabalin per se did not show any significant effect on above mentioned behaviour.

\section{Effect on tactile mechanical hyperalgesia}

CCI resulted in the development of tactile mechanical hyperalgesia as reflected by a significant increase in the left hind paw lifting duration in the pinprick test (Figure 6), as compared to sham group. Administration of hydroalcoholic extract of $A C(100$ and $200 \mathrm{mg} / \mathrm{kg})$ attenuated CCI induced increase in the hind paw lifting duration i.e. tactile mechanical hyperalgesia [59.5\% \pm
0.013 and $74.27 \% \pm 0.016$ (inhibition \pm SEM) $]$ in a dose dependent manner. Treatment of pregabalin also produced similar effects $[87.78 \% \pm 0.029$ (inhibition \pm SEM)]. However, the vehicle administration did not modulate $\mathrm{CCI}$ induced tactile mechanical hyperalgesia. Moreover, $A C$ as well as pregabalin per se did not show any significant effect on above mentioned behaviour.

\section{Effect on mechanical allodynia}

CCI resulted in the development of tactile mechanical allodynia as reflected by a significant increase in the left hind paw withdrawal threshold in the Von Frey Hair test (Figure 7), as compared to sham group. Administration of hydroalcoholic extract of $A C(100$ and $200 \mathrm{mg} /$ $\mathrm{kg}$ ) attenuated CCI induced increase in the left hind paw lifting duration i.e. mechanical allodynia $[67.99 \% \pm$ 0.024 and $81.08 \% \pm 0.026$ (inhibition \pm SEM)] in a dose dependent manner. Treatment of pregabalin also produced similar effects $[90.53 \% \pm 0.032$ (inhibition \pm SEM)]. However, the vehicle administration did not modulate CCI induced mechanical allodynia. Moreover, 


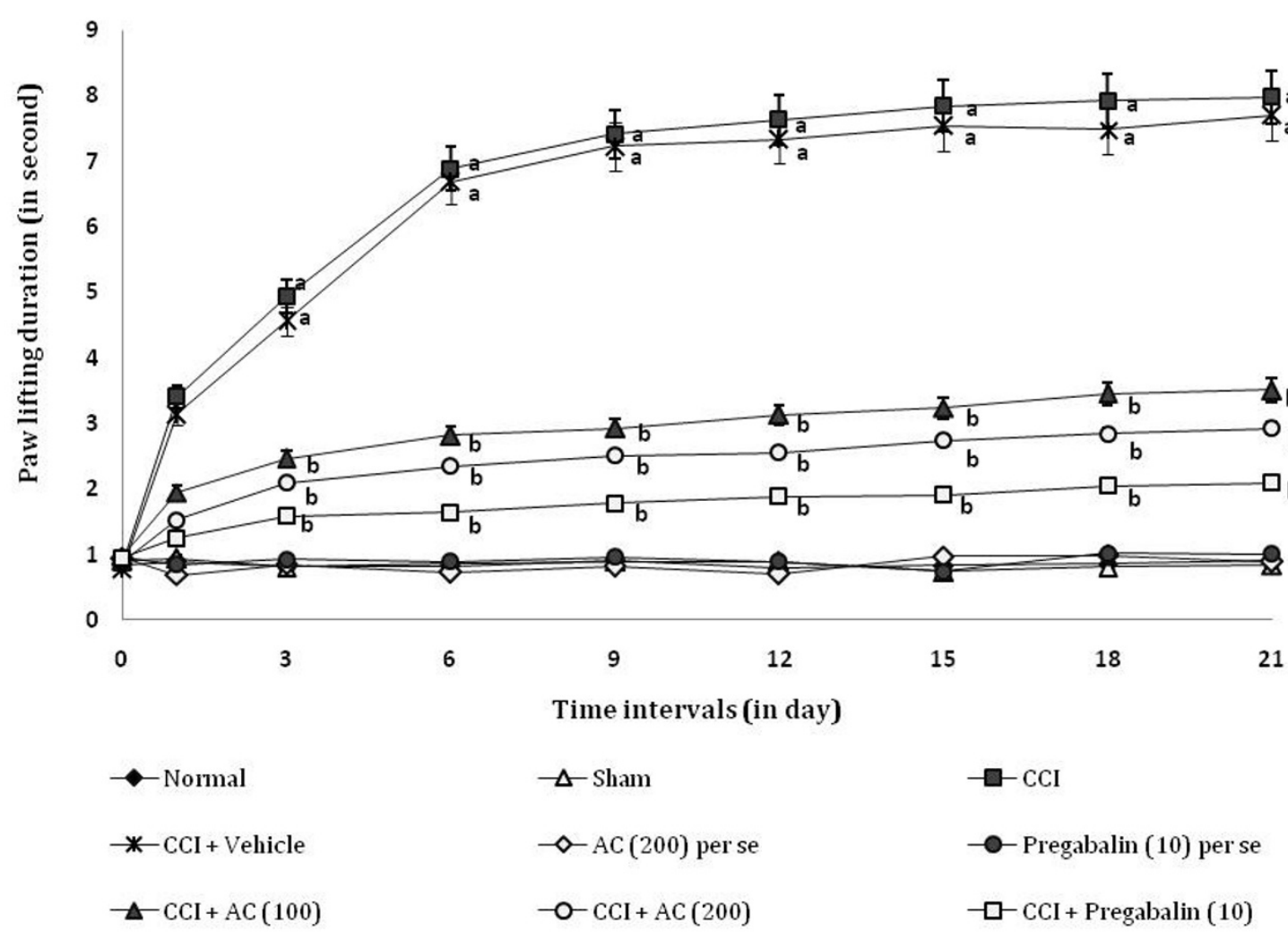

Figure 4 Effect of Acorus calamus on cold chemical allodynia assessed by the non-noxious chemical stimuli evoked ipsilateral hind paw lifting duration. Digits in parentheses indicate the dose of Acorus calamus and pregabalin in mg/kg. Data expressed as mean \pm standard error of mean (SEM), each group consist of six $(n=6)$ Wistar rat. ${ }^{a} p<0.05$ vs sham control group. ${ }^{\mathbf{b}} p<0.05$ vs CCI control group.

$A C$ as well as pregabalin per se did not show any significant effect on above mentioned behaviour.

\section{Effect on tissue biomarker changes}

CCI resulted in a significant increase in the levels of superoxide anion and total calcium in sciatic nerve and myeloperoxidase activity in surrounding tissue of sciatic nerve, as compared to sham group. Administration of the hydroalcoholic extract of $A C$ (100 and $200 \mathrm{mg} / \mathrm{kg} p$. $o$.) significantly attenuated CCI induced increase in the levels of superoxide anion $[77.39 \% \pm 1.18$ and $86.46 \% \pm$ 1.07 (inhibition \pm SEM)], total calcium $[75.16 \% \pm 1.61$ and $84.21 \% \pm 1.34$ (inhibition \pm SEM) $]$ and myeloperoxidase $[76.62 \% \pm 4.13$ and $82.28 \% \pm 3.36$ (inhibition \pm SEM)] levels, in a dose dependent manner. Treatment of pregabalin also produced similar effects on superoxide anion generation $[98.39 \% \pm 0.19$ (inhibition \pm SEM)], total calcium $[98.31 \% \pm 1.91$ (inhibition \pm SEM) $]$ and myeloperoxidase activity $98.87 \% \pm 1.21$ ]. However, the vehicle administration did not modulate CCI induced alteration in the superoxide anion generation and the total calcium levels. Moreover, as well as pregabalin $A C$ per se did not show any significant effect on above mentioned biochemical levels (Table 1).

\section{Effect on histopathological changes}

CCI resulted in significant histopathological changes assessed in transverses section of the sciatic nerve. In transverse section, nerve derangement, axonal swelling, increase in number of Schwann and satellite cells were also noted. Administration of the hydroalcoholic extract of $A C$ (100 and $200 \mathrm{mg} / \mathrm{kg}$ p.o.) significantly attenuated CCI induced fiber derangement, swelling of nerve fiber and activation of neuroglial cell (satellite cells and Schwann cells) as marker of histopathological alterations (Figure 8). Microscopic examinations were performed under $450 \times$ light microcopy, scale bar $35 \mu \mathrm{m}$.

\section{Discussion}

In the present study, Acorus calamus attenuated sciatic nerve ligation i.e., chronic constriction injury induced behavioural [i.e., thermal, radiant, mechanical, chemical sensation (hyperalgesia and allodynia)], biochemical (superoxide anion, myeloperoxidase and total calcium) 


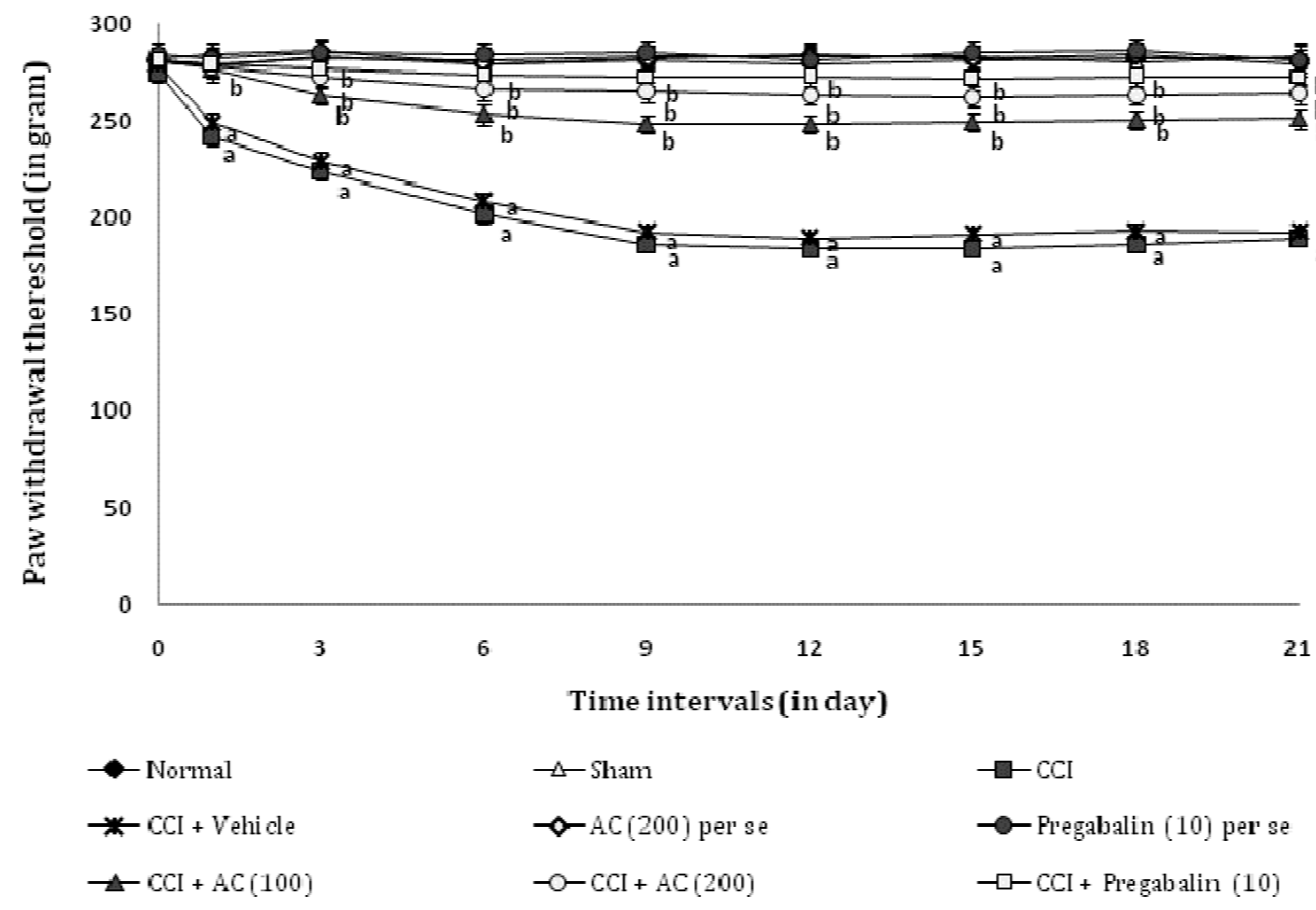

Figure 5 Effect of Acorus calamus on static mechanical hyperalgesia assessed by the noxious mechanical stimuli evoked ipsilateral hind paw withdrawal threshold. Digits in parentheses indicate the dose of Acorus calamus and pregabalin in mg/kg. Data expressed as mean \pm standard error of mean (SEM), each group consist of six $(n=6)$ Wistar rat. ${ }^{a} p<0.05$ vs sham control group. ${ }^{\mathbf{b}} p<0.05$ vs CCl control group.

and histopathological (axonal degeneration) changes. However no significant effect on motor-coordination and spontaneous (locomotor or exploratory) motor activity was observed. The behavioural alterations started on $3^{\text {rd }}$ day after the chronic constriction injury of sciatic nerve and lasted throughout the experimental period. These observations are in line with our earlier findings $[32,56]$ and reports from the other laboratories $[57,22]$. In response to an injury to a nerve, initial steps of inflammatory reactions, involve the release of proinflammatory mediators from the resident macrophages, Schwann cells and area adjacent to nerve lesion [58]. It has been documented that the sustained activation of peripheral nociceptors leads to the hypersensitivity of the primary afferent neurons and central sensitization of the dorsal horn neurons [4].

Neuropathic pain (including CCI of sciatic nerve) has been demonstrated to produce a rise in tissue total calcium levels [55,59]. Further, a key role of calcium accumulation has also been reported in formalin, posttraumatic, axotomy, CCI and vincristine-induced models of neuropathic pain $[32,55,60]$. Calcium ion accumulation has been documented to trigger the secondary messengers i.e., activation of calcium binding protein (calpain and calmodulin) and calcium dependent kinase and phosphatase action. It can alter the homeostasis function of nervous system and enhancement of autodestruction including long term potentiation, long term depression and neuronal hyper-excitation [61]. Calciuminduced activation of calpains has been shown to be responsible for the axonal degeneration by alteration of stability of axonal cytoskeleton protein [62].

Several studies evidenced that free radical and calcium mediated oxidative stress and inflammation together play a major role in the pathogenesis of neurodegenerative diseases, such as amyotrophic lateral sclerosis, Alzheimer's disease, Parkinson's disease and neuropathic pain $[55,63,64]$. Moreover, reactive oxygen and nitrogen species have also been well documented to contribute in the pathophysiological changes in long standing diabetes, toxin, Freund's adjuvant induced inflammation, chronic constriction injury and axotomy of sciatic nerve and ischemia-reperfusion of femoral artery mediated neuropathic pain $[2,32,55,64-66]$.

In the present study, Acorus calamus has been observed to attenuate CCI induced behavioural, biochemical as well as histopathological changes. Acorus calamus is reported to exert a battery of beneficial 


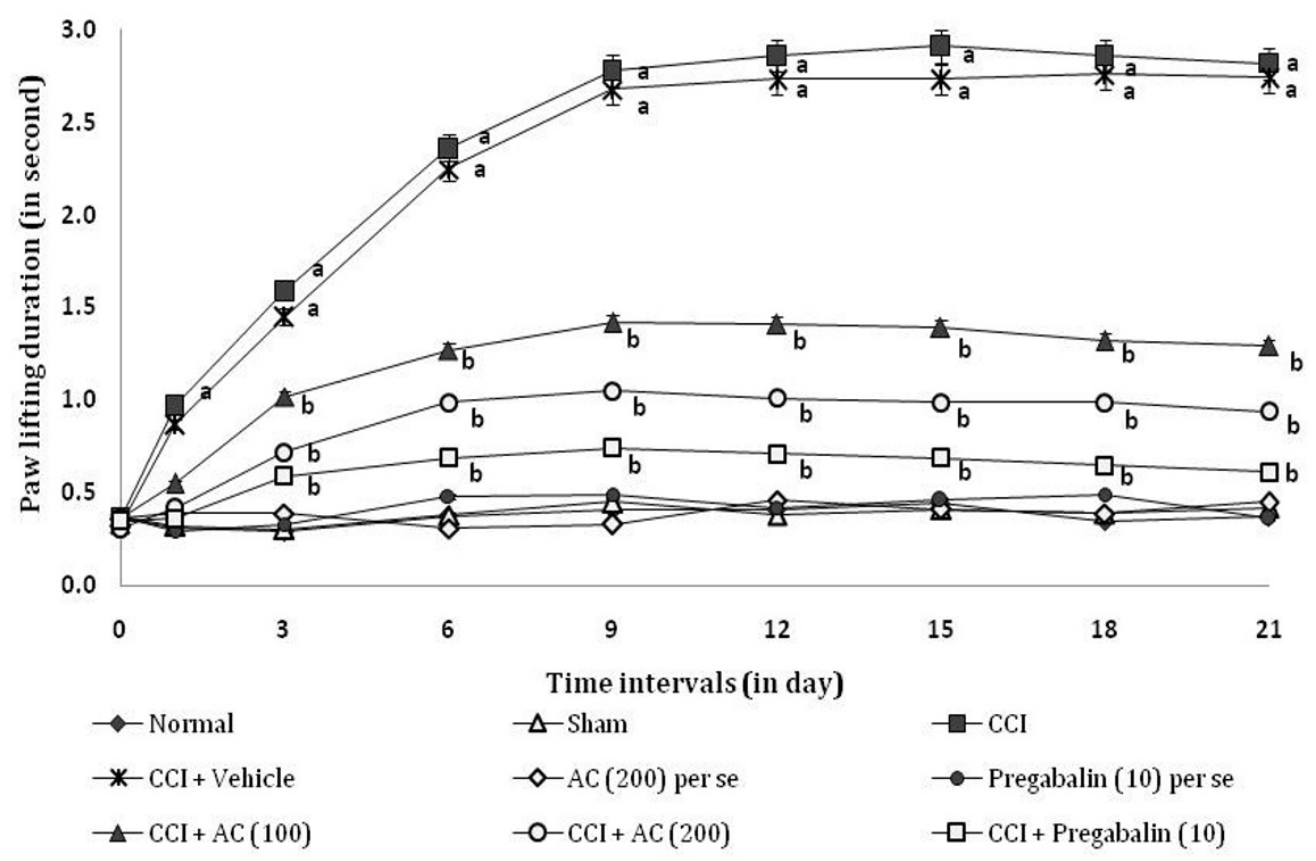

Figure 6 Effect of Acorus calamus on tactile mechanical hyperalgesia assessed by the noxious mechanical stimuli evoked ipsilateral hind paw withdrawal duration. Digits in parentheses indicate the dose of Acorus calamus and pregabalin in mg/kg. Data expressed as mean \pm standard error of mean (SEM), each group consist of six $(n=6)$ Wistar rat. ${ }^{\mathbf{a}} p<0.05$ vs sham control group. ${ }^{\mathbf{b}} p<0.05$ vs CCI control group.

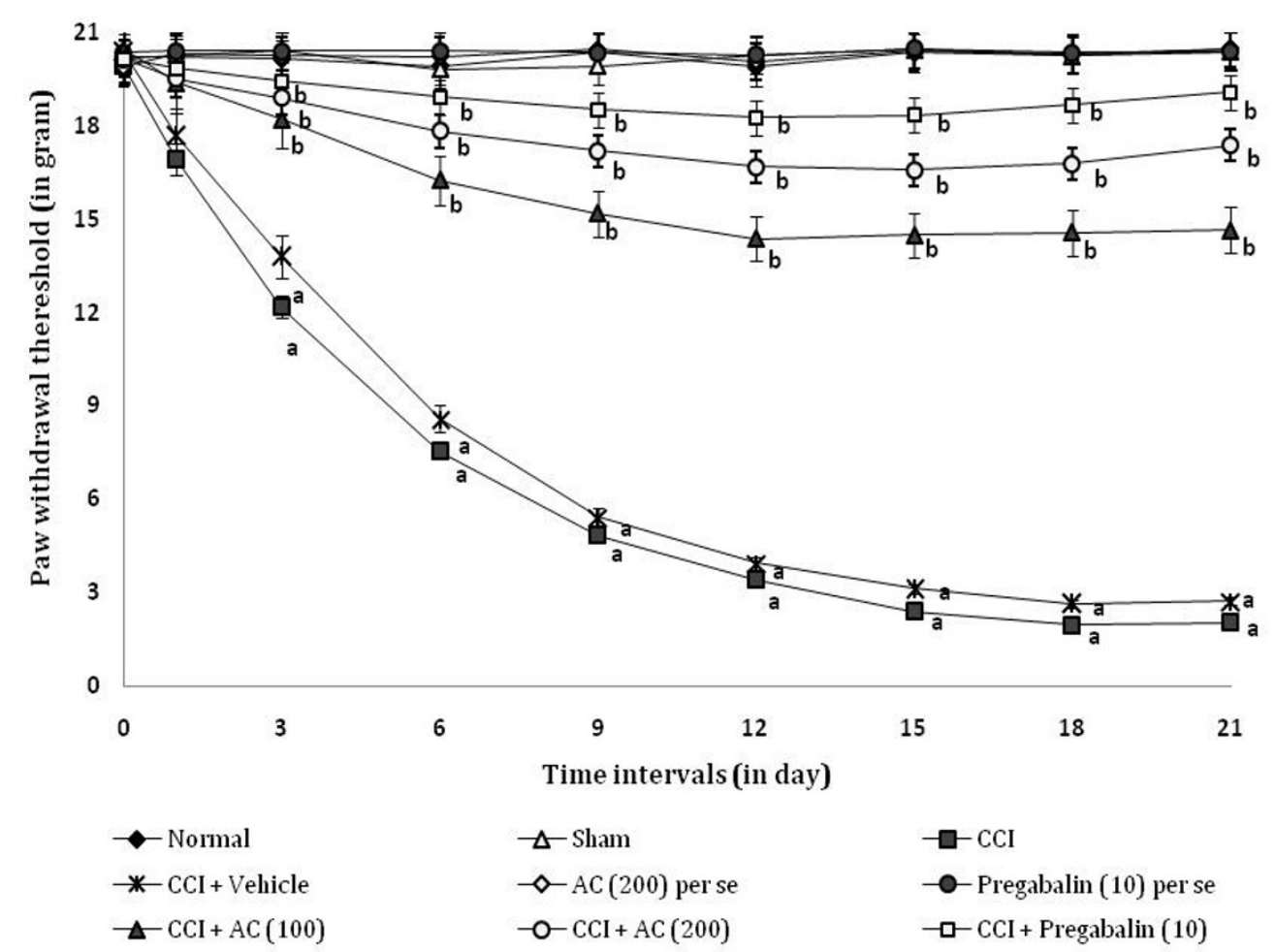

Figure 7 Effect of Acorus calamus on mechanical allodynia assessed by the non-noxious mechanical stimuli evoked ipsilateral hind paw withdrawal threshold. Digits in parentheses indicate the dose of Acorus calamus and pregabalin in $\mathrm{mg} / \mathrm{kg}$. Data expressed as mean \pm standard error of mean (SEM), each group consist of six $(n=6)$ Wistar rat. ${ }^{\mathbf{a}} p<0.05$ vs sham control group. ${ }^{\mathbf{b}} p<0.05$ vs $C C l$ control group. 
Table 1 Effect of Acorus calamus on tissue biomarker changes

\begin{tabular}{llll}
\hline Groups & $\begin{array}{l}\text { Reduction of NBT } \\
\text { (pmol/min/mg of protein) }\end{array}$ & $\begin{array}{l}\text { Total Calcium } \\
\text { (ppm/mg of protein) }\end{array}$ & $\begin{array}{l}\text { MPO activity level } \\
\text { (U/min/mg of protein) }\end{array}$ \\
\hline Normal & $3.38 \pm 1.18$ & $3.92 \pm 1.12$ & $10.12 \pm 1.04$ \\
Sham & $3.42 \pm 1.45$ & $3.35 \pm 0.73$ & $12.37 \pm 1.83$ \\
CCl & $21.56 \pm 1.26^{\mathbf{a}}$ & $33.43 \pm 1.51^{\mathbf{a}}$ & $165.24 \pm 3.89^{\mathbf{a}}$ \\
CCl + vehicle & $22.88 \pm 1.69^{\mathbf{a}}$ & $37.36 \pm 1.38^{\mathbf{a}}$ & $159.63 \pm 4.01^{\mathbf{a}}$ \\
AC (200) per se & $3.40 \pm 1.19$ & $3.57 \pm 0.64$ & $11.94 \pm 1.09$ \\
Pregabalin (10) per se & $3.38 \pm 1.23$ & $3.25 \pm 1.17$ & $12.08 \pm 0.92$ \\
CCI + AC (100) & $7.49 \pm 1.18^{\mathbf{b}}$ & $11.26 \pm 1.61^{\mathbf{b}}$ & $47.36 \pm 4.13^{\mathbf{b}}$ \\
CCI + AC (200) & $5.84 \pm 1.07^{\mathbf{b}}$ & $8.59 \pm 1.34^{\mathbf{b}}$ & $38.65 \pm 3.36^{\mathbf{b}}$ \\
CCl + Pregabalin (10) & $3.27 \pm 0.19^{\mathbf{b}}$ & $4.43 \pm 1.91^{\mathbf{b}}$ & $13.14 \pm 1.21^{\mathbf{b}}$ \\
\hline
\end{tabular}

Digits in parentheses indicate the dose of Acorus calamus and pregabalin in $\mathrm{mg} / \mathrm{kg}$.

Data expressed as mean \pm standard error of mean (SEM), each group consist of six $(n=6)$ Wistar rat.

${ }^{a} p<0.05$ vs sham control group.

${ }^{\mathrm{b}} p<0.05$ vs $\mathrm{CCl}$ control group.

effects in various ailments viz; epilepsy, memory deficits, rheumatic pain, neuralgia $[38,39,67]$. Ethanolic extract of $A C$ has been reported to exert anti-cellular, immunosuppression actions along with inhibition of nitric oxide, interleukin-2 and tumor necrosis factor-alpha productions and blocking of voltage activated calcium channel $[68,69]$. Further ethanolic extract of $A C$ has also been demonstrated to possess potential anti-oxidative, anti- inflammatory as well as neuroprotective actions [70-72]. Experimentally, it has also been reported to decrease free radical generation via enhancement of anti-oxidant mechanisms such as increase in superoxide dismutase, catalase, reduced glutathione and glutathione peroxidase levels [73]. Additionally, it is shown to be a neuroprotective action against the hypoxic (ischemia) event and chemical (i.e., acrylamide) induced severe insult in
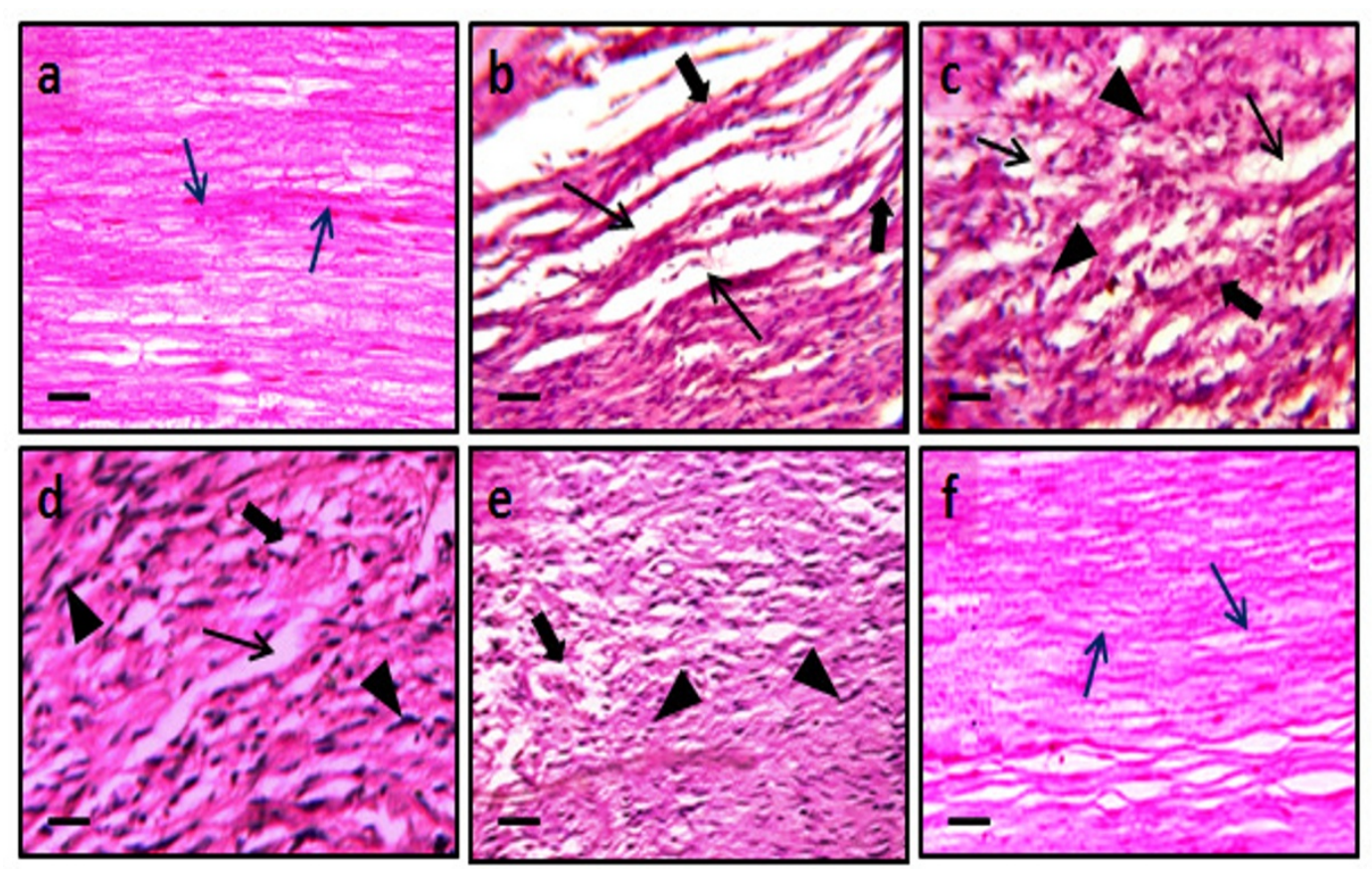

Figure 8 Effect of Acorus calamus on chronic constriction injury induced histopathological changes. Figures $8 \mathrm{a}-8 \mathrm{f}$ show transverse-section of sciatic nerve of sham, CCl, vehicle, AC (100 and $200 \mathrm{mg} / \mathrm{kg})$ and pregabalin pretreated groups respectively. In figure 8a and 8f, blue arrow shows normal fiber arrangement. In figures 8b-8e, black arrows show fiber derangement (thin arrow), swelling (bold arrow) of nerve fiber and presence of activated satellite cells and Schwann cells (arrow head). In figures $8 \mathrm{~d}-8 \mathrm{f}$, show attenuation of CCl induced swelling of nerve fibers by AC (100 and $200 \mathrm{mg} / \mathrm{kg}$ ) and pregabalin pretreatment groups respectively. Microscopic examinations were performed under $450 \times$ light microcopy, scale bar $35 \mu \mathrm{m}$. 
nervous system $[74,75,61]$. On the basis of data in hand and with support from literature, therefore, it may be proposed that hydroalcoholic extract of $A C$ rhizome produced ameliorative effect in CCI induced painful peripheral neuropathy which may be attributed to its multiple effects viz; anti-oxidative, anti-inflammatory, and neuroprotective actions manifested in the terms of alleviation of CCI induced behavioural (hyperalgesia and allodynia), biochemical (superoxide anions, total calcium and MPO activity) as well as histopathological changes. Our findings support the contention that generation of reactive oxygen species, calcium channel over-activation and inflammation may be a major culprit in the axonal degeneration and pathogenesis of neuropathic pain.

Pregabalin [(S)-3-(aminomethyl)-5-methylhexanoic acid or $\mathrm{S}-(+)$ - isomer of 3 - isobutyl $\gamma$-aminobutyric acid] is an anti-convulsant that successfully treats many neuropathic pain syndromes [76]. Pregabalin is an Selective $\mathrm{Ca}_{\mathrm{v}} 2.2$ ( $\alpha 2-\delta$ subunit) channel antagonist. It has potential actions like predecessor gabapentin, it's a structural analogue (but not functional) of the gamma aminobutyric acid. Pregabalin has analgesic, anti-convulsant and anxiolytic activities [77]. Preclinical trials have demonstrated an anti-hyperalgesic and anti-allodynic effect of pregabalin in various animal models of neuropathic pain $[76,78,79]$. Data of our study also supports these reports.

Since pregabalin is well documented to exert its beneficial effect in neuropathic pain via inhibition of voltage gated calcium $\left[\mathrm{Ca}_{\mathrm{V}} 2.2\right.$ ( $\alpha 2-\delta$ subunit)] channels and Acorus calamus has also been shown to modulate calcium channel activity [68]. Therefore, it is proposed that in addition to its potential anti-oxidative, anti-inflammatory and neuroprotective actions, voltage activated calcium channel $\left[\mathrm{Ca}_{\mathrm{V}} 2.2(\alpha 2-\delta\right.$ subunit)] modulatory action of Acorus calamus may be an important factor in attenuating CCI induced peripheral neuropathic pain. Nevertheless further studies are needed to substantiate these findings.

\section{Conclusion}

Acorus calamus attenuated the chronic constriction injury induced behavioural, biochemical and histopathological changes in rats. These effects may be attributed to its potential anti-oxidative, anti-inflammatory, neuroprotective and calcium inhibitory actions.

\footnotetext{
Acknowledgements

The authors acknowledge the financial support from Council of Scientific and Industrial Research (CSIR) through the research scheme no. 01 (2344)/ 09-EMR-II. The authors are also thankful to Department of Pharmaceutical Sciences \& Drug Research, Punjabi University, Patiala (India) for providing technical facilities for the work. Authors are grateful to Mr. Amteshwar Singh Jaggi, Assistant professor, Department of Pharmaceutical Sciences \& Drug Research for his valuable technical suggestion.
}

\section{Authors' contributions}

AM participated in the experimental study and performed for the statistical analysis. NS participated in its design and helped to draft the manuscript. All authors read and approved the final manuscript for publication.

\section{Competing interests}

The authors declare that they have no competing interests.

Received: 26 October 2010 Accepted: 22 March 2011

Published: 22 March 2011

\section{References}

1. Carlton SM, Du J, Tan HY, Nesic O, Hargett GL, Bopp AC, Yamani A, Lin Q, Willis WD, Hulsebosch CE: Peripheral and central sensitization in remote spinal cord regions contribute to central neuropathic pain after spinal cord injury. Pain 2009, 147:265-276.

2. Muthuraman A, Ramesh M, Sood S: Development of animal model for vasculatic neuropathy: Induction by ischemic-reperfusion in the rat femoral artery. J Neurosci Methods 2010, 186:215-221.

3. Wall PD, Waxman SG, Basbaum Al: Ongoing activity in peripheral nerve: injury discharge. Exp Neurol 1974, 45:576-589.

4. Woolf CJ, Mannion RJ: Neuropathic pain: aetiology, symptoms, mechanisms, and management. Lancet 1999, 353:1959-1964

5. Alston RP, Pechon P: Dysaesthesia associated with sternotomy for heart surgery. Br J Anaesth 2005, 95:153-158.

6. Garg R, Dehran M: Leprosy: a precipitating factor for complex regional pain syndrome. Minerva Anestesiol 2010, 76:758-760.

7. Koltzenburg M, Scadding J: Neuropathic pain. Curr Opin Neurol 2001, 14:641-647.

8. Shaladi AM, Saltari MR, Crestani F, Piva B: Post-surgical neuropathic pain. Recenti Prog Med 2009, 100:371-379.

9. Weisz GM, Houang M, Bogduk N: Complex regional pain syndrome associated with cervical disc protrusion and foraminotomy. Pain Med 2010.

10. Bennett GJ, Xie YK: A peripheral mononeuropathy in rat that produces disorders of pain sensation like those seen in man. Pain 1988, 33:87-107.

11. Kramer HH, He L, Lu B, Birklein F, Sommer C: Increased pain and neurogenic inflammation in mice deficient of neutral endopeptidase. Neurobiol Dis 2009, 35:177-183.

12. Kurvers $H$, Daemen $M$, Slaaf $D$, Stassen $F$, van den Wildenberg F, Kitslaar $P$ de Mey J: Partial peripheral neuropathy and denervation induced adrenoceptor supersensitivity. Functional studies in an experimental model. Acta Orthop Belg 1998, 64:64-70.

13. Nagler RM: CRPS: Central aspects related to locus of pain, pathophysiology, and mood. Neurology 2010, 75:109-110.

14. Chae J: Poststroke complex regional pain syndrome. Top Stroke Rehabil 2010, 17:151-162.

15. Herlyn P, Müller-Hilke B, Wendt M, Hecker M, Mittlmeier T, Gradl G: Frequencies of polymorphisms in cytokines, neurotransmitters and adrenergic receptors in patients with complex regional pain syndrome type I after distal radial fracture. Clin J Pain 2010, 26:175-181.

16. Li WW, Guo TZ, Liang D, Shi X, Wei T, Kingery WS, Clark JD: The NALP1 inflammasome controls cytokine production and nociception in a rat fracture model of complex regional pain syndrome. Pain 2009, 147:277-286.

17. Toms AD, Mandalia $V$, Haigh $R$, Hopwood B: The management of patients with painful total knee replacement. J Bone Joint Surg Br 2009, 91:143-150.

18. Botez SA, Herrmann DN: Sensory neuropathies, from symptoms to treatment. Curr Opin Neurol 2010, 23:502-508.

19. Driessen B, Bauquier SH, Zarucco L: Neuropathic pain management in chronic laminitis. Vet Clin North Am Equine Pract 2010, 26:315-337.

20. Dwight EM: The clinical management of neuropathic pain. Pain Res Manag 2006, 11:30A-36A.

21. Dworkin RH, O'Connor AB, Audette J, Baron R, Gourlay GK, Haanpää ML, Kent JL, Krane EJ, Lebel AA, Levy RM, Mackey SC, Mayer J, Miaskowski C, Raja SN, Rice AS, Schmader KE, Stacey B, Stanos S, Treede RD, Turk DC, Walco GA, Wells CD: Recommendations for the pharmacological management of neuropathic pain: an overview and literature update. Mayo Clin Proc 2010, 85:S3-S14.

22. Lee $\mathrm{BH}$, Won $\mathrm{R}$, Baik EJ, Lee $\mathrm{SH}$, Moon $\mathrm{CH}$ : An animal model of neuropathic pain employing injury to the sciatic nerve branches. Neuroreport 2000, 11:657-661. 
23. Carol W, Jane K: Evidence based treatment of diabetic peripheral neuropathy. J Nurse Pract 2006, 2:370-378.

24. Hama AT, Plum AW, Sagen J: Antinociceptive effect of ambroxol in rats with neuropathic spinal cord injury pain. Pharmacol Biochem Behav.

25. Wiffen PJ, Collins S, McQuay HJ, Carroll D, Jadad A, Moore RA: WITHDRAWN. anticonvulsant drugs for acute and chronic pain. Cochrane Database Syst Rev 2010, 1:CD001133.

26. Kalita J, Vajpayee A, Misra UK: Comparison of prednisolone with piroxicam in complex regional pain syndrome following stroke: a randomized controlled trial. Q J Med 2006, 99:89-95.

27. Kumar K, Taylor RS, Jacques L, Eldabe S, Meglio M, Molet J, Thomson S, O'Callaghan J, Eisenberg E, Milbouw G, Buchser E, Fortini G, Richardson J, North RB: Spinal cord stimulation versus conventional medical management for neuropathic pain: a multicentre randomised controlled trial in patients with failed back surgery syndrome. Pain 2007, 132:179-188.

28. Thomson $S$, Jacques $L$ : Demographic characteristics of patients with severe neuropathic pain secondary to failed back surgery syndrome. Pain Pract 2009, 9:206-215.

29. Comelli F, Giagnoni G, Bettoni I, Colleoni M, Costa B: Antihyperalgesic effect of a Cannabis sativa extract in a rat model of neuropathic pain: mechanisms involved. Phytother Res 2008, 8:1017-1024.

30. Kanter M: Effects of Nigella sativa and its major constituent, thymoquinone on sciatic nerves in experimental diabetic neuropathy. Neurochem Res 2008, 1:87-96.

31. Kim YS, Park HJ, Kim TK, Moon DE, Lee HJ: The effects of Ginkgo biloba extract EGb 761 on mechanical and cold allodynia in a rat model of neuropathic pain. Anesth Analg 2009, 108:1958-1963.

32. Muthuraman $A$, Diwan $V$, Jaggi AS, Singh N, Singh D: Ameliorative effects of Ocimum sanctum in sciatic nerve transection Induced neuropathy in rats. J Ethnopharmacol 2008, 120:56-62.

33. Wirth $J H$, Hudgins JC, Paice JA: Use of herbal therapies to relieve pain: A review of efficacy and adverse effects. Pain Manag Nurs 2005, 6:145-167.

34. Babbar S, Marier JF, Mouksassi MS, Beliveau M, Vanhove GF, Chanda S, Bley K: Pharmacokinetic analysis of capsaicin after topical administration of a high-concentration capsaicin patch to patients with peripheral neuropathic pain. Ther Drug Monit 2009, 31:502-510.

35. Ellis RJ, Toperoff W, Vaida F, van den Brande G, Gonzales J, Gouaux B, Bentley H, Atkinson JH: Smoked medicinal cannabis for neuropathic pain in HIV: a randomized, crossover clinical trial. Neuropsychopharmacology 2009, 34:672-680.

36. Nurmikko TJ, Serpell MG, Hoggart B, Toomey PJ, Morlion BJ, Haines D: Sativex successfully treats neuropathic pain characterised by allodynia: a randomised, double-blind, placebo-controlled clinical trial. Pain 2007, 133:210-220.

37. Duke JA: In CRC handbook of medicinal herbs Boca Raton: CRC Press; 1985.

38. Mittal N, Ginwal HS, Varshney VK: Pharmaceutical and biotechnological potential of Acorus calamus Linn: An indigenous highly valued medicinal plant species. Pharmacog Rev 2009, 3:83-93.

39. Martis G, Rao A, Karanth KS: Neuropharmacological activity of Acorus calamus. Fitoterapia 1991, 4:331-337.

40. Parap RS, Mengi SA: Evaluation of hypolipidemic activity of Acrous calamus Linn in rats. Indian Drugs 2003, 40:25-29.

41. Muthuraman A, Singh N, Jaggi AS: Effect of hydroalcoholic extract of Acorus calamus on tibial and sural nerve transection-induced painful neuropathy in rats. J Nat Med 2011, 65:282-292.

42. Sommer C, Schafers M: Painful mononeuropathy in C57BL/WId mice with delayed wallerian degeneration: differential effects of cytokine production and nerve regeneration on thermal and mechanical hypersensitivity. Brain Res 1998, 784:154-162.

43. Eddy NB, Touchberry CF, Lieberman JE: Synthetic analgesics: I. Methadone isomers and derivatives. J Pharmacol Exp Ther 1950, 98:121-137.

44. Hargreaves K, Dubner R, Brown F, Flores C, Joris J: A new and sensitive method for measuring thermal nociception in cutaneous hyperalgesia. Pain 1988, 32:77-88.

45. Choi Y, Yoon YW, Na HS, Kim SH, Chung JM: Behavioural signs of ongoing pain and cold allodynia in a rat model of neuropathic pain. Pain 1994, 59:369-376.

46. Randall LO, Selitto J: A method for measurement of analgesic activity of inflamed tissue. Arch Int Pharmacodyn Ther 1957, 111:409-419.
47. Erichsen HK, Blackburn-Munro G: Pharmacological characterization of the spared nerve injury model of neuropathic pain. Pain 2002, 98:151-161.

48. Chaplan SR, Bach FW, Pogrel JW, Chung JM, Yaksh TL: Quantitative assessment of tactile allodynia in the rat paw. J Neurosci Methods 1994, 53:55-63.

49. Jones BJ, Roberts DJ: The quantitative measurement of motor incoordination in naive mice using an accelerating rotarod. $J$ Pharm Pharmacol 1968, 20:302-304.

50. Goddard M, Zheng Y, Darlington CL, Smith PF: Locomotor and exploratory behavior in the rat following bilateral vestibular deafferentation. Behav Neurosci 2008, 122:448-459.

51. Wang HD, Pagano PJ, Du Y, Cayatte AJ, Quinn MT, Brecher P, Cohen RA: Superoxide anion from the adventitia of the rat thoracic aorta inactivates nitric oxide. Circ Res 1998, 82:810-818.

52. Lowry OH, Rosenbrough NJ, Farr AL, Randall RJ: Protein measurement with folin phenol reagent. J Biol Chem 1951, 193:265-275.

53. Grisham MB, Specian RD, Zimmerman TE: Effects of nitric oxide synthase inhibition on the pathophysiology observed in a model of chronic granulomatous colitis. J Pharmacol Exp Ther 1994, 271:1114-1121.

54. Severinghaus JW, Ferrebee JW: Calcium determination by flame photometry; methods for serum, urine, and other fluids. J Biol Chem 1950, 187:621-630.

55. Muthuraman A, Jaggi AS, Singh N, Singh D: Ameliorative effects of amiloride and pralidoxime in chronic constriction injury and vincristineinduced painful neuropathy in rats. Eur J Pharmacol 2008, 587:104-111.

56. Sudoh Y, Desai SP, Haderer AE, Sudoh S, Gerner P, Anthony DC, De Girolami U, Wang GK: Neurologic and histopathologic evaluation after high volume intrathecal amitriptyline. Reg Anesth Pain Med 2004, 29:434-440.

57. Cui JG, Holmin S, Mathiesen T, Meyerson BA, Linderoth B: Possible role of inflammatory mediators in tactile hypersensitivity in rat models of mononeuropathy. Pain 2000, 88:239-248.

58. Marchand F, Perretti M, MCMahon SB: Role of immune system in chronic pain. Nat Rev Neurosci 2005, 6:521-532.

59. Jain $\mathrm{V}$, Jaggi $\mathrm{AS}$, Singh $\mathrm{N}$ : Ameliorative potential of rosiglitazone in tibial and sural nerve transection-induced painful neuropathy in rats. Pharmacol Res 2009, 59:385-392.

60. Siau C, Bennett GJ: Dysregulation of neuronal calcium homeostasis in chemotherapy-evoked painful peripheral neuropathy. Anesth Analg 2006, 102:1485-1490.

61. Young W: Role of calcium in central nervous system injuries. J Neurotrauma 1992, 9:9-25.

62. Glass JD, Culver DG, Levey Al, Nash NR: Very early activation of m-calpain in peripheral nerve during Wallerian degeneration. J Neurol Sci 2002, 196:9-20.

63. Honda K, Casadesus G, Petersen RB, Perry G, Smith MA: Oxidative stress and redox-active iron in Alzheimer's disease. Ann N Y Acad Sci 2004, 1012:179-182.

64. Muthuraman A, Sood S: Pharmacological evaluation of tacrolimus (FK506) on ischemia reperfusion induced vasculatic neuropathic pain in rats. J Brachial Plex Peripher Nerve Inj 2010, 5:13-23.

65. Gao X, Kim HK, Chung JM, Chung K: Reactive oxygen species (ROS) are involved in enhancement of NMDA-receptor phosphorylation in animal models of pain. Pain 2007, 131:262-271

66. Otto M, Bak S, Bach FW, Jensen TS, Sindrup SH: Pain phenomena and possible mechanisms in patients with painful polyneuropathy. Pain 2003, 101:187-192.

67. Rafatullah S, Tariq M, Mossa JS, Al-Yahya MA, Al-Said MS, Ageel AM: Antisecretagogue, anti-ulcer and cytoprotective proberties of Acorus calamus in rats. Fitotherpia 1994, 65:19-23.

68. Gilani AU, Shah AJ, Ahmad M, Shaheen F: Antispasmodic effect of Acorus calamus Linn. is mediated through calcium channel blockade. Phytother Res 2006, 20:1080-1084.

69. Mehrotra S, Mishra KP, Maurya R, Srimal RC, Yadav VS, Pandey R, Singh VK: Anticellular and immunosuppressive properties of ethanolic extract of Acorus calamus rhizome. Int Immunopharmacol 2003, 3:53-61.

70. Manikandan S, Srikumar R, Jeya Parthasarathy N, Sheela Devi R: Protective effect of Acorus calamus Linn on free radical scavengers and lipid peroxidation in discrete regions of brain against noise stress exposed rat. Biol Pharm Bull 2005, 28:2327-2330.

71. Tippani R, Porika M, Rao AV, Abbagani S, Yellu NR, Tammidala C: Analgesic activity of root extract of Acorus calamus Linn. Pharmacologyonline 2008, 3:240-243 
72. Yang L, Li S, Huang Y, Liang J, Wang Y: Effects of Acorus gramineus and its component, alpha-asarone, on apoptosis of hippocampal neurons after seizure in immature rats. Neural Reg Res 2008, 3:19-24.

73. Geetha RK, Vasudevan DM: Inhibition of lipid peroxidation by botanical extracts of Ocimum sanctum: In vivo and in vitro studies. Life Sci 2004, 76:21-28.

74. Hazra R, Ray K, Guha D: Inhibitory role of Acorus calamus in ferric chloride-induced epileptogenesis in rat. Hum Exp Toxicol 2007, 26:947-953.

75. Shukla PK, Khanna VK, Ali MM, Maurya R, Khan MY, Srimal RC: Neuroprotective effect of Acorus calamus against middle cerebral artery occlusion-induced ischaemia in rat. Hum Exp Toxicol 2006, 25:187-194.

76. Kumar N, Laferriere A, Yu JS, Leavitt A, Coderre TJ: Evidence that pregabalin reduces neuropathic pain by inhibiting the spinal release of glutamate. J Neurochem 2010, 113:552-561.

77. Stump P: Pregabalin-profile of efficacy and tolerability in neuropathic pain. Drugs Today (Barc) 2009, 45:19-27.

78. Bender G, Florian JA Jr, Bramwell S, Field MJ, Tan KK, Marshall S, DeJongh J, Bies RR, Danhof M: Pharmacokinetic-pharmacodynamic analysis of the static allodynia response to pregabalin and sildenafil in a rat model of neuropathic pain. J Pharmacol Exp Ther 2010, 334:599-608.

79. Park HJ, Joo HS, Chang HW, Lee JY, Hong SH, Lee Y, Moon DE: Attenuation of neuropathy-induced allodynia following intraplantar injection of pregabalin. Can J Anaesth 2010, 57:664-671.

Pre-publication history

The pre-publication history for this paper can be accessed here: http://www.biomedcentral.com/1472-6882/11/24/prepub

doi:10.1186/1472-6882-11-24

Cite this article as: Muthuraman and Singh: Attenuating effect of Acorus calamus extract in chronic constriction injury induced neuropathic pain in rats: an evidence of anti-oxidative, anti-inflammatory,

neuroprotective and calcium inhibitory effects. BMC Complementary and Alternative Medicine 2011 11:24.

\section{Submit your next manuscript to BioMed Central and take full advantage of:}

- Convenient online submission

- Thorough peer review

- No space constraints or color figure charges

- Immediate publication on acceptance

- Inclusion in PubMed, CAS, Scopus and Google Scholar

- Research which is freely available for redistribution

Submit your manuscript at www.biomedcentral.com/submit 